\title{
Entrevista com Laura Mulvey
}

Revista Estudos Feministas: Este ano é o $30^{\circ}$ aniversário da publicação de seu artigo "Visual Pleasure and Narrative Cinema". Esse artigo é um marco tanto para os estudos feministas do cinema como para os estudos de cinema como um todo - e no Brasil é o seu trabalho mais conhecido. Nesse texto você utiliza a psicanálise para fazer uma profunda crítica da imagem no cinema convencional como produzida pelo e para o olhar masculino. Qual é o seu balanço hoje do impacto desse artigo no momento em que foi publicado e na trajetória posterior dos estudos feministas de cinema?

Laura Mulvey: A primeira consideração que eu gostaria de fazer é que esse artigo foi escrito em um contexto particular. Ele foi escrito antes da consolidação dos estudos de cinema na Inglaterra, ou talvez no momento em que os estudos de cinema estavam começando a ser pensados. Mas o artigo foi escrito mais sob o impacto do movimento de mulheres do que dos estudos de cinema. E eu penso que existe uma força e uma fragilidade nisso. Eu penso que a força é que o artigo foi escrito de forma polêmica e retórica, em uma maneira de pensar que vem mais de um movimento políitico do que do contexto acadêmico. Ele não tem notas de rodapé. Ele não faz contra-argumentos. Ele procura sustentar fortemente seu próprio ponto de vista. Ele tem uma estrutura cuidadosamente modelada para que todas as partes possam ser vistas se encaixando umas nas outras, como um quebra-cabeça. E eu penso que essa é uma das razões pelas quais o artigo perdurou. Ele também foi escrito na forma de sound bites, como se diz hoje em dia - não se usava essa expressão naquela época -, o que quer dizer que muitas de suas frases podem ser facilmente extraídas do texto e citadas. Essa forma em que ele foi pensado e concebido veio muito mais de um modo político de pensar do que de um modo acadêmico. Por um lado, isso significa que ele tem um certo impacto, ou vigor, ou força, que contribuiu para sua longevidade. Por outro lado, ele não tem aquelas qualidades acadêmicas da reflexão cuidadosa e da argumentação minuciosa. Assim, eu imagino que deve ter sido talvez difícil de integrá-lo no discurso dos estudos de cinema. Mas obviamente ele o foi, ele foi publicado numerosas vezes, traduzido em muitas línguas, e adquiriu esse particular status de ícone. Eu ainda diria a respeito do contexto no qual o artigo foi escrito que o meu amor ao cinema e à cinefilia que alimentei durante alguns anos foram sobretudo um amor pelo cinema hollywoodiano, que nós aqui em Londres absorvemos pelo contexto francês, pelos Cahiers du Cinéma e por Paris. Em um certo sentido, essa cinefilia era também polêmica na medida em que ela combinava dois aspectos da rejeição da anglicidade e da 
cultura inglesa tradicional, na qual tudo o que era inglês era 0 melhor do mundo, particularmente a literatura inglesa, e na qual existia uma grande diferença entre as culturas de elite, por exemplo a literatura inglesa, e a corrosiva cultura do popular, particularmente representada por hollywood e pela cultura popular norteamericana. Assim, no início dos anos 60, como uma forma de rebelião contra essa tradicional anglicidade, apoiar a cultura popular norte-americana de um ponto de vista da alta cultura era uma provocação ao establishment inglês, o qual respondeu conforme o esperado. E essa provocação tornou-se também mais forte devido à influência da França, das teorias francesas, de LéviStrauss e do estruturalismo, do primeiro impacto da psicanálise. Assim, para o establishment inglês, combinar cultura popular norteamericana e teoria francesa era deixar o inimigo entrar pelos dois lados. E mesmo enquanto meu artigo estava questionando o cinema hollywoodiano, meu quadro de referência era ainda aquele cinema. Era usar aquele cinema para criar um debate sério, não para descartá-lo como algo sem nenhum interesse estético. Era ainda levar esse cinema a sério, algo a partir do qual era possível o questionamento psicanalítico e estrutural e semiótico. Assim, existia um duplo movimento que era muito importante naquela época.

REF: Você falou sobre como suas opiniões no contexto político da época influenciaram seu trabalho. É interessante pensar em como, desde 1975 até agora, você teve uma influência não apenas sobre o pensamento político como também sobre o acadêmico.

LM: Eu diria que o impacto do artigo foi completamente inesperado, e que eu estava pensando sobretudo sobre questões de representação que surgiram no movimento de mulheres, como por exemplo a idéia de que a representação teria que ser pensada semiótica e psicanaliticamente e não apenas como um reflexo do social. Nesse sentido, o argumento também estava contemplando a política, mas ao mesmo tempo a intelectualização do argumento estava claramente se deslocando para um tipo diferente de discurso, mais acadêmico. Naquela época eu diria que ele era mais dirigido a uma intelligentsia; eu não pensava em termos acadêmicos, porque eu não estava envolvida na academia e não tinha nenhum interesse em estar. Naquela época nós pensávamos mais em termos de uma intelligentsia de esquerda e não em termos de uma academia.

REF: Quando você começou a dar aulas?

LM: Eu tive alguns pequenos contratos de meio-turno como professora no final dos anos 70 e obtive a minha primeira posição fixa em 1980. 
REF: Ao mesmo tempo a psicanálise é uma influência na teoria do cinema ainda hoje. Como você vê a potencialidade da psicanálise para compreender o cinema hoje e para discutir questões de representação?

LM: Para mim pessoalmente, talvez a psicanálise tenha sido uma das mais importantes influências, particularmente a psicanálise freudiana. Para voltar um pouco no tempo, eu participei de um grupo de leitura no início dos anos 70 , onde nós começamos a ler Freud e percebemos que, embora Freud possa não ter pensado sobre feminismo, ele pensou sobre questões da sexualidade feminina em uma sociedade patriarcal, o que teve na época muita ressonância para nós. Então, mesmo que nós não fôssemos necessariamente absorver o pensamento freudiano de forma acrítica, a linguagem e o quadro conceitual que ele proporcionou nos permitiram pensar, sobre representação em particular, de uma forma muito profícua. Particularmente dissociando a imagem da mulher de reflexo para sintoma, e assim pensá-la como sintomática da circulação de imagens em uma cultura, pode-se dizer patriarcal e mercantilizada, como uma representação do inconsciente masculino. Assim, esse descolamento da imagem do referente foi muito importante, além de ter sido enriquecido com questões de referência mais no uso lacaniano da linguística e da psicanálise, onde essa referência não se dá em relação a um objeto original, mas a outros significantes, formando cadeias de significado.

REF: Em "Afterthoughts..." você discute esses dois elementos, a personagem feminina como heroína do filme e o olhar masculino da mulher como espectadora - ou seja, na posição masculina. $O$ olhar masculino não como olhar do homem, mas como uma posição.

LM: Como uma posição, exato. E me parece que essa posição que as mulheres podiam adotar no cinema era ao mesmo tempo repressiva e liberadora. Era liberadora no sentido de que era uma experiência de um distanciamento do olhar, possibilitando a compreensão de que se trata de uma posição contingencial e não essencial. $E$ isso era interessante também porque, uma vez que a consciência desse olhar contingente emergia, era possível se ter um olhar mais curioso - tema que eu tento desenvolver posteriormente -, um olhar de curiosidade sobre o que estou olhando, mais propriamente do que "eu sou apenas o sujeito da tela". Assim, com um distanciamento, percebe-se que o que eu havia argumentado sob a influência do feminismo e do movimento de mulheres, a facilidade da posição de prazer, havia se transformado em algo desconfortável e difícil. Alem disso, a consciência da imagem produzida não era algo que poderia acontecer somente com as mulheres, mas começaria a afetar as formas através das quais o cinema poderia ser visto - e esse foi o caminho pelo qual meu artigo "Visual Pleasure..." deslocou-se para 
o que hoje consideramos um utopismo absurdo, a sensação que sentíamos naquela época de que poderíamos reinventar o cinema, como diria Godard um retorno ao zero - e esse argumento teórico ficou intimamente ligado à tentativa de fazer um novo cinema, uma vanguarda.

REF: Em Frida Kahlo \& Tina Modotti você tenta mostrar outro tipo de olhar, diferente de apenas prazer e gozo, a figura feminina sendo representada como sofrimento e como trabalho e em ação.

LM: Sim.

REF: Especialmente falando dessas duas figuras, que tentaram, de acordo com o documentário, modificar, transformar o olhar, você acha que é possível um deslocamento do olhar masculino e a criação de uma outra forma de olhar?

LM: Sim, certamente naquele momento eu achava. Talvez isso seja mais significativo em Riddles of the Sphinx, o filme que nós fizemos nos anos 70. O Frida Kahlo \& Tina Modotti era mais o registro da exposição que nós fizemos, mas também foi importante para dizer que, buscando uma alternativa às representações patriarcais das mulheres, não existe apenas uma resposta - existem diferentes caminhos pelos quais mulheres artistas podem explorar a questão da representação das mulheres. E que essas duas mulheres artistas tiveram abordagens diferentes mas complementares.

REF: Em Riddles of the Sphinx pode-se ver muito de seu artigo "Visual Pleasure...". É uma forma de diálogo, não sei se você concorda. Entre seus textos e seus filmes existe uma forma de diálogo?

LM: Sim, existe. E também porque eu estava trabalhando com Peter Wollen, há também a questão dos textos dele, "The Two AvantGardes" por exemplo, e o compromisso dele com o cinema de vanguarda, que era de qualquer maneira talvez mais significativo que o meu, em todo caso naquela época.

\section{REF: Enquanto linguagem?}

LM: Sim, e uma das questões que nós estávamos colocando sobre a estética do cinema era: seria possível expandir a linguagem do cinema sem passar pelo desvio de negar o cinema convencional? E assim, bastante influenciados pelas teorias da época, estávamos

Planos-sequência advogados na teoria da "montagem proibida" de André Bazin, teórico e crítico do cinema e um dos co-fundadores dos Cahiers du Cinéma. tentanto trabalhar com tomadas extensas, do tipo das tomadas bazinianas, ${ }^{1}$ planos longos nos quais se poderia levar a questão do ponto de vista e da fonte do olhar para além da tela, mas também anular o ponto de vista dos diretores do filme. A parte central do filme [Riddles of the Sphinx] é composta por 13 tomadas circulares, que chegam a um final não quando o diretor diz "basta", 
2 Termo francês proveniente da pintura empregado no teatro principalmente por Bertold Brecht, o que veio a influenciar o cinema, indicando a narrativa estruturada em fragmentos auto-uficientes. mas sim ao final do círculo. Nós estávamos interessados na forma pela qual o cinema cria seus próprios padrões, ou o círculo cria seu próprio padrão.

REF: Ao mesmo tempo você tem o corte de cada fragmento, e cada fragmento tem sua própria totalidade.

LM: Sim, e isso também faria uma certa referência ao tableau, seria mais propriamente uma frisa do que um tableau, ${ }^{2}$ a idéia de algo que tem sua integridade, completo em si mesmo.

REF: E novamente, em um certo ponto do filme, quando você mostra no espelho a pessoa que está filmando, assim você está tentando expor o mecanismo do filme, e mesmo seu reflexo.

LM: Não sou eu; é a cinegrafista.

REF: Mas quando você está falando?

LM: Ah sim, aí sou eu.

REF: No começo e no final.

LM: Sim, eu apareço.

REF: A presença da artista.

LM: E no filme anterior que nós fizemos, Penthesilea, Peter aparece em um monólogo muito longo em uma das seções do filme.

REF: Voltando à questão do olhar, o dualismo ativo e passivo é uma referência na discussão do olhar masculino. Ele é um produto da matriz heterossexual da sexualidade que está presente não na psicanálise mas em algumas interpretações. Se você tenta escapar dessa matriz, isso não desestabilizaria a idéia da imagem feminina correspondendo ao olhar masculino? O que significaria, para a produção e para a interpretação das imagens no cinema, a introdução de outras formas de desejo que escapem dessa hegemonia? Por exemplo, algumas novas produções, e mesmo outras formas de desejo e de olhar, não apenas em relação ao olhar masculino, mas ao olhar masculino branco ocidental - essas novas realizações vindas do leste...

LM: Tais como?

REF: O cinema iraniano, algumas experimentações. A questão é se existe alguma possibilidade de escapar dessa matriz, da idéia de que nossa imagem está ligada à idéia de dominação, controlada pelo olhar masculino. 
LM: Quando escrevi o meu artigo, eu estava realmente pensando no sistema de estúdio hollywoodiano. Eu realmente não estava tentando analisar todo o cinema e dizer que esse é um aspecto essencial do cinema, embora o artigo tenha sido interpretado como dizendo isso, como se todo tipo de olhar fosse necessariamente um tipo de olhar intrusivo. E também eu penso que, quando você revê esse cinema, ele era menos monolíico. Mesmo o cinema holywoodiano era menos monolítico do que eu talvez tenha mostrado, por isso acho que os aspectos retóricos e polêmicos do artigo têm que ser enfatizados. A questão era abrir um debate, a questão não era ser justo. E claramente existiriam muitos outros cinemas que estariam experimentando diferentes modos de olhar. Outros cinemas importantes para mim foram, por exemplo, o do diretor senegalês Ousmane Sembene...

\section{REF: Ele dirigiu Xala?}

LM: Xala, sim, sobre o qual eu escrevi. E recentemente tenho estado muito interessada no novo cinema iraniano. E as questões que esse cinema coloca para mim podem às vezes ser muito complexas, já que o cinema que nós estávamos reivindicando nos anos 70 - não apenas eu, mas as teóricas feministas em geral - era um tipo de cinema iconoclástico, no qual a questão da representação da mulher, senão impossível, era questionada, ou seja, a necessidade de voltar ao grau zero e de desfamiliarizar a forma pela qual as mulheres eram vistas. Então, em um certo sentido, eu estou perplexa com o fato de que, vindo da outra ponta do espectro, o cinema que vem da República Islâmica do Irã também está questionando a representação das mulheres e colocando em crise a questão da representação das mulheres, do ponto de vista do mulá e não do ponto de vista das feministas. Mas eu penso que o interessante no caso do Irã é que o cinema, e sua estética, conquistou lá um lugar tão duradouro na sociedade que o tabu em torno da representação das mulheres fez de fato com que as pessoas questionassem de que maneira as mulheres podem ser representadas. Assim, eu penso que existe um deslocamento daquele tipo de censura por parte do mulá para a realização de filmes muito interessantes, particularmente aqueles feitos por mulheres, porque existem provavelmente mais mulheres fazendo cinema no Irã do que em muitos outros países. Certamente na França existem muitas mulheres fazendo cinema, mas muitos outros países, mesmo aqui [a Inglaterra], não poderiam dizer o mesmo.

REF: Mulheres realizadoras fazendo filmes sobre mulheres... por exemplo o último filme de Samira Makhmalbaf é sobre eleições e uma mulher tentando...

LM: Uma mulher candidatando-se para o Parlamento, exato. 
REF: At Five in the Afternoon, sim, e é interessante que o filme não é sobre o Irã, mas sobre o Afeganistão.

LM: Mas mesmo um filme como Ten, de Abbas Kiarostami, está tentando encontrar um modo de falar sobre a questão das mulheres, e ele ironicamente faz do espaço do automóvel um espaço de questionamento e diálogo. Mas eu também admiro o cinema de Rakhshan Bani Etemad, uma diretora que tem feito filmes já há algum tempo, que eu considero muito brilhante e que talvez faça filmes em um gênero levemente mais popular do que o cinema de arte que nós podemos ver aqui.

REF: Em uma conferência em Florianópolis, Michel Marie (professor de cinema na Universidade de Sorbonne - Paris III) falou sobre as novas tecnologias, sobretudo as digitais, que possibilitam que muitas pessoas possam facilmente fazer filmes na França, mas que as poucas produções que ele considera interessantes, originais e realmente 'novas' são alguns filmes feitos por mulheres realizadoras. E que os críticos masculinos têm ignorado essas novas produções. Você acha que o fato de as mulheres poderem produzir mais agora do que, digamos, 30 anos atrás pode significar uma mudança no cinema e no olhar?

LM: Sim, exatamente como a tecnologia do $16 \mathrm{~mm}$ trouxe uma outra forma de olhar e abriu muito mais o cinema para as mulheres nos anos 60 e 70. A tecnologia digital tem feito mais diferença ainda, talvez não somente para as mulheres, mas também para pessoas tentando documentar situações de opressão. Palestinos tentando documentar sua condição, mulheres militantes israelenses indo para a Palestina e tentando filmar o que acontece nos postos de controle na fronteira. Nesse sentido, o cinema digital pode atuar como uma espécie de força de documentação, o que é particularmente útil nesses momentos de confronto. Eu penso que nessas situações ele se torna particularmente importante.

REF: É interessante, porque em seu artigo "Visual Pleasure..." você fala sobre a potencialidade dos $16 \mathrm{~mm}$. Você vê o mesmo potencial nas tecnologias digitais? De que forma elas poderiam realmente fazer a diferença?

LM: O problema é também um problema de distribuição e acesso e de como você consegue ver esses filmes, porque eles não circulam tão facilmente. O problema do consumo ainda não foi realmente resolvido, exatamente como na época dos $16 \mathrm{~mm}$, quando muito se pensou sobre como esses filmes poderiam encontrar formas alternativas de distribuição. Provavelmente isso também está acontecendo agora, mas talvez eu simplesmente não saiba de que forma isso está acontecendo. Mesmo assim, eu penso que a habilidade de fazer circular imagens e histórias, mesmo 
de uma forma mais informal, menos esteticizada, mais vinda do cotidiano, do tipo um filme-diário, será muito importante.

REF: E você acha que existe uma nova janela mais aberta hoje para o documentário do que para a ficção?

LM: Eu penso que no momento, não sei exatamente por que, existe um interesse particular no documentário. Talvez porque as pessoas percebem que o mundo mudou tão rapidamente nos últimos $10 \mathrm{a}$ 15 anos, que é mais interessante documentar a mudança e pensar sobre o que está acontecendo com o mundo do que assistir a ficção. Eu percebi, durante o London Film Festival, que há cada vez mais documentários sendo mostrados, e que quando eu estava tomando nota do que eu gostaria de ver intuitivamente eu acabava tendendo para o documentário mais do que para filmes de ficção. Existem alguns lugares aqui que estão tentando promover o acesso a esses documentários. Existe uma organização chamada In the DocHouse, que fez alguns arranjos com os cinemas Riverside e The Other Cinema - antes de este último fechar -, onde, por exemplo, nas tardes de domingo eles mostrariam documentários recentes que ainda não foram mostrados em nenhum outro lugar.

REF: Mesmo nos grandes cinemas você pode ver mais documentários ultimamente. E em relação à distribuição, há ainda hoje a possibilidade do vídeo e do DVD e também da internet como um espaço de distribuição.

LM: Certamente eles também estão aparecendo em DVD, e aí você tem uma combinação desde documentários no estilo arte até algumas coisas como Control Room - o documentário sobre a Al-Jazeera. Definitivamente, mesmo que esses filmes não sejam mostrados nos cinemas, eles são vistos e se escreve sobre eles.

REF: É interessante essa idéia de que o cinema digital possa ser usado nesses espaços específicos de conflito. Três semanas atrás foi mostrado um documentário aqui em Londres sobre o trabalho de três mil jornalistas baseados na fronteira do Kuwait com o Iraque.

LM: Ohh!

REF: Muito interessante. O diretor, um espanhol que vive em Londres, foi lá com uma pequena câmera - o orçamento era realmente baixo - e ele seguiu alguns jornalistas que ainda não tinham nenhuma informação sobre a guerra, mas já transmitindo para outros países. Eles estavam fora da guerra, e o documentário mostra como eles estavam tentando entrar no Iraque através do Kuwait. Essas são algumas possibilidades, especialmente no caso dessas zonas de conflito. 
LM: Não foi algumas semanas atrás que uma freira foi assassinada na Amazônia?

REF: Sim.

LM: No Brasil, e ela não estava filmando quando foi assassinada?

REF: Não tenho muita certeza disso. Mas voltando à discussão do poder das imagens, para algumas teóricas feministas nós vivemos hoje sob um regime escopofílico - onde a força da imagem transcende a arte, a mídia e a narrativa; transcende a representação e contamina a vida. Seria a imagem, nos dias de hoje, o 'real'? Por exemplo, a imagem da mulher que circula na mídia tornou-se um significante central, não apenas para o olhar masculino, mas para o processo de subjetivação e construção de mulheres como sujeitos. Assim, nós vivemos um novo regime do corpo, de construção corporal, mulheres tentando se adaptar a essas imagens poderosas de beleza. Na medida em que as imagens vêm para o real elas se tornam o real, não são mais representação. Como você vê o poder da imagem na cultura contemporânea, transcendendo o cinema?

LM: Eu suponho que necessariamente temos de admitir que o cinema é apenas um entre muitos outros meios de circulação de imagens hoje. Enquanto que para grande parte do século XX ele foi a forma suprema, hoje ele é mais uma forma entre outras. $E$ numa certa medida ele foi superado em seu diálogo com as novas tecnologias, particularmente as digitais. Isso pode ter algo a ver com o novo interesse em documentário do qual falávamos antes, ao passo que, olhando para trás, o período no qual a realidade foi inscrita em película, em filmes onde o fotográfico era cinemático, foi na realidade surpreendentemente curto. Porque, mesmo que você possa dizer que sempre foi possível manipular um negativo, a manipulação era ao mesmo tempo bem mais visível, e não a criação invisível proporcionada pela tecnologia digital, na qual você pode tanto mudar a imagem como criar a imagem do nada, tornando tudo de certo modo questionável. Parece-me interessante hoje que o tipo de questão que nós colocamos nos anos 70 sobre referência, a tentativa de separar o referente da imagem da mulher das mulheres reais, tenha talvez sido completamente revertido, e que hoje nós estejamos sentindo uma insegurança devido à perda da referencialidade na sociedade contemporânea. E junto com isso essa mudança geral na ideologia da política humanista liberal, em que a retórica do político se transformou em pura fabricação! E ao mesmo tempo o mecânico e o industrial foram tão anulados nas primeiras sociedades industrializadas que há muito menos sentido de realidade inscrito em nossas imagens. Hoje o desafio é tentar recolocar a questão da realidade e da verdade da representação. E mesmo que você assuma, a partir de uma perspectiva lacaniana, que a verdade será alusiva e difícil de 
alcançar e finalmente inapreensível, ao mesmo tempo eu penso que a aspiração de tentar alcançá-la tem uma importância hoje. REF: Você acha que é mais difícil hoje romper o ilusionismo (por exemplo mostrando a artista)?

LM: Eu acho que até um certo ponto esse tipo de diálogo entre artista e produto se tornou muito mais generalizado hoje, porque o DVD permite uma presença muito maior, entrevistas, os artistas dizendo o que eles querem dizer; existe muita documentação da produção das imagens. Eu penso que essa é uma questão sempre interessante e importante, mas eu não tenho certeza de que hoje tenha aquela presença radical que tinha anteriormente.

REF: Nos DVDs você tem toda essa documentação - quase uma outra ficção. Alguns DVDs vêm com dois discos, um com o filme, outro com todo o resto, making off - você pode mesmo assistir ao filme com os comentários do diretor em off. Mas quanto ao apelo da película, você acha que a tecnologia digital pode substituir esse apelo?

LM: O que me interessa no momento, algo sobre o qual eu tenho escrito bastante recentemente, é a forma pela qual a chegada das tecnologias digitais afetou os filmes realizados em película. Assim, mais propriamente do que pensar em ambos como opostos - o digital eliminando o cinema -, eu tenho tentado pensar nas formas pelas quais a tecnologia digital pode manter o velho cinema vivo e em circulação, mas também produzir novas formas de ver o filme e transformar a relação entre espectador e os filmes do passado, através de diferentes dispositivos. Assim, por exemplo, na época em que eu escrevi "Visual Pleasure..." a única maneira de ver um filme era no escuro, com projetor rodando 24 quadros por minuto, em que o modo de o espectador olhar o filme vinha da tela, ou pelo menos era o que eu discutia naquela época. Ao passo que hoje me parece que você tem uma forma de ver o filme muito mais interativa, e algumas das questões que eu tinha levantado naquele artigo efetivamente aconteceram - você pode repetir ou retornar a um ponto particular. A linearidade do filme começa a ser fragmentada em diferentes cenas, diferentes padrões, e você pode ver coisas que até agora eram mais ou menos invisíveis. Eu tenho pensado em maneiras pelas quais o cinema do passado possa ser distendido, e em formas distendidas de ver um filme, as quais eu também associo a uma política da demora. A precipitação em direção às novas tecnologias, em direção ao futuro, acarreta o anulamento do passado, como quando nossos líderes políticos anunciaram o fim de uma era, como eles fizeram no 11 de setembro de 2001, e isso de certo modo tenta riscar uma linha debaixo da história e rechaçar as tradições da modernidade e o utopismo de esquerda - ambos fortemente associados à história do cinema e ao pensamento do século XX. 
E, obviamente, alguém como Godard em Histoires du Cinéma está olhando para o cinema como história do século XX, apesar de ele talvez estar olhando para o cinema não como uma força liberadora mas como uma força conservadora. Ao mesmo tempo eu acho importante ver no cinema 1. histórias conflituosas; 2 . uma história do desejo utópico e 3. ver a maneira pela qual o próprio tempo pode ser modificado, mudado. Como no cinema de vanguarda pré-1929, quando pessoas como Vertov, Epstein e René Clair, e outros, viam o cinema não como restrito à ilusão do movimento, mas proporcionando diferentes modos de ver o mundo. Eu diria que hoje nós podemos usar o quadro-a-quadro, a repetição, a pausa como um novo modo de ver o mundo do cinema que cresceu paralelo ao mundo real durante o século XX. E podemos ver que o cinema por inteiro não está esgotado mas que talvez nós tenhamos visto apenas a ponta do iceberg, não apenas pensando nos filmes de ficção, nos filmes de Hollywood, nas novas formas de prazer no gesto e no controle, o que eu chamo de modo possessivo de ver um filme, mas também pensando no que eu chamaria de um tipo de audiência reflexiva, refletindo sobre os interstícios das tomadas e sobre a questão da representação do tempo. E também pensar em como o filme, que parecia não ter nenhum uso ou relevância, passa a ter isso agora simplesmente porque ele é do passado. Fui apresentada a um filme, uns dois anos atrás, feito por um realizador holandês, em que ele usa tomadas muito bonitas feitas por um escritório colonial holandês, documentando todo o processo de colonização da Indonésia. Um filme de 90 minutos no qual você vê a vida das pessoas sendo transformadas de um estado, digamos, 'primitivo' entre aspas para um trabalho mecanizado de produção de tabaco - o cultivo, a colheita, a seleção e o amontoamento de todo o tabaco para exportar. Assim, num certo sentido, é um modo fascinante de olhar histórias ocultas assim como um meio alternativo de ver filmes famosos.

REF: Essa mudança na forma da audiência não teria vindo também com o vídeo?

LM: Sim, isso é totalmente verdadeiro. Eu penso que nós acumulamos essa nova maneira de ver as coisas, e freqüentemente quando tentamos encontrar alguma coisa no DVD é bem mais difícil do que no vídeo e quase insuportável. Eu acho que o problema com o vídeo é que a imagem era muito imperfeita quando você pausava - o laser disc era muito bom, mas infelizmente foi uma tecnologia de curta duração. Porém, eu acho que nós simplesmente temos de encontrar um modo de trabalhar, preparar melhor. Talvez o DVD torne-se um pouco mais fácil de lidar, mas eu ainda o acho muito difícil - você aperta o botão errado e você está de volta ao começo. 
REF: É interessante que, mudando as formas de ver o filme, mesmo diretores hollywoodianos mudaram seus velhos filmes - novas cópias digitais de filmes como Apocalypse Now, novas versões, versões modificadas...

LM: De várias maneiras tudo isso mantém vivo o velho cinema. Existe uma relação dialética entre o velho e o novo aqui que é muito interessante e que vai nos dois sentidos, não apenas na direção do digital.

REF: Um novo modo de ver velhos filmes.

LM: Sim.

REF: Isso também aconteceu com a chegada da internet. Alguns pensavam que as pessoas não leriam mais livros - em papel. Mas talvez com a internet as pessoas leiam e escrevam mais do que antes. Não se está eliminando os livros, mas...

LM: ... encontrando diferentes pontos de entrada.

REF: Você está trabalhando atualmente em um novo livro sobre todas essas questões?

LM: Ele está quase pronto. Eu sempre digo "amanhã". Eu não estou totalmente contente com ele, mas isso é o que eles querem que eu faça no Brasil no verão, falar sobre essas coisas.

REF: Quando ele será lançado?

LM: Se eu conseguir entregar os originais na próxima semana, ele deve sair durante 2005. Assim, a pressão é grande para que eu entregue logo o manuscrito.

REF: Nós esperamos que ele chegue ao Brasil também. Muito obrigada.

LM: Obrigada a vocês.

Londres, março de 2005.

Tradução: Sônia Weidner Maluf Revisão da tradução: Cecilia Antakly de Melo

362 Estudos Feministas, Florianópolis, 13(2): 351-362, maio-agosto/2005 